\title{
The Knowledge of Batak Toba Family in Feeding Toddler at Muliorejo Village, Sunggal District, Deli Serdang Regency
}

\author{
Kristina Mutiara Sihombing and Nurman Achmad \\ Universitas Sumatera Utara, Indonesia \\ kristina@gmail.com
}

Key Words: $\quad$ Nutrition Anthropology, Dietary Habbit, Eating Habbit.

\begin{abstract}
This study examines the knowledge of Batak Toba family in feeding toddlers in Muliorejo Village, Sunggal District, Deli Serdang Regency. The purpose of this study was to determine the knowledge of Batak Toba family in feeding toddler, how to serve toddler food, selecting toddler food and managing toddler food. The method used in this study is a holistic ethnographic method. The data collection technique used is through in-depth interviews, observation, and participation in the community, having knowledge related to research problems, and studying literature. The results of this study prove that the knowledge of Batak Toba family in feeding toddlers is very good, where parents who feed their children provide with a regular schedule in feeding, when the child is not at home or when the parents are at work, they keep fulfill the child's food by entrusting food to neighbors to give to his child, by also preparing provisions for the child.
\end{abstract}

\section{INTRODUCTION}

The success of a nation is determined by the availability of quality human resources (HR), namely human resources who have strong physical, strong mental, and excellent health. Children are the future assets of the nation and state that determine the survival, quality and glory of a nation in the future. Therefore, children need to be conditioned so that they can grow and develop optimally and be educated as well as possible so that in the future they can become the next generation with good character and personality.

The age of children under five years is a very crucial age for children's development and can determine the future of children related to the ability of the brain and endurance. Generally, at the age of toddlers, what affects the growth process is nutritional problems.

Children's health is health which ensures that they always eat nutritious food. So that parents must give the best for their children so that eating must be well maintained, so that it can provide good growth for children, where at this time children are no longer considered properly by parents for children in terms of food. Concern about children's health is very important in the knowledge of mothers who will care for and nurture children so that children grow well.

Nutritional status has a very big influence in realizing quality human resources in the future related to children's intelligence. The formation of intelligence in early childhood depends on the intake of nutrients received. The lower the intake of nutrients received, the lower the nutritional status and health of children. Undernourishment or poor nutrition in infancy and childhood, especially at the age of less than 5 years can lead to disruption of physical growth and intelligence of children (Health Department of the Republic of Indonesia, 2002).

Toddlers are born with ignorance about life in the world. That is why toddlers will always ask all things related to the natural world, accompanied by curiosity and a great thirst for knowledge. So toddlers really like new things. such as, seeing a mother sweeping the house, a toddler who is two years old, this toddler must immediately imitate the work that the mother does (Horton PB, 2006:27).

Food as a cultural system is an expressive activity, which is related to social aspects, symbolic roles, economy, religion, beliefs, and sanctions. 
Food as a cultural system includes issues of food concepts, personal preferences, appetite, and hunger, food clarification, and the symbolic role of food (Foster and Anderson 1986: 313-322; Kalangi 1985: 46-50). Culturally, there are rules and values regarding food, which include: selection of food ingredients, food concepts, meal times, types of food, and eating etiquette. Dietary habbit at a certain time forms a physiological adjustment that creates a reaction in the form of hunger at that time. This culturally regulated eating pattern will form a physiological adjustment, which gives rise to a reaction, namely in the form of appetite, which is a cultural concept that differs in each community.

In Batak Mandailing tribe, the food of toddlers when they first get food is food cooked in a hudon or a place to cook rice using burned wood. After the rice is half cooked, the rice is made in a plastic cup which mixes various types of vegetables such as potatoes, tomatoes to taste in a cup and adds salt to add flavor to the child's food.

Whereas in Batak Toba tribe it is not much different from giving children food for the first time after exclusive breastfeeding for children, where this knowledge until now in Batak Toba Community there are still families who provide children's food with food made as before, the only difference is that now the era of sophisticated tools. the current cooking method so that it makes children's food in a rice cooker using electricity.

Food is culturally an expression of the bonds of social life, because the acquisition (production) of food can be done individually. Socially, food is an expression of love, care, and friendship. The culture of reciprocating in the giving and receiving of food is an expression of social bonds that should not be underestimated. In social life, offering food or drink can be considered as an offer of affection, attention and friendship. The person who accepts the offered food will acknowledge and accept the expressed order and to reciprocate. On the other hand, not giving food or failing to offer food in a cultural context, can be considered as expressing anger or hostility. Similarly, refusing an offered food may be considered refusing an offer of affection, friendship, and expressing hostility towards the giver.

Food can serve as a way to maintain family ties and friendships. Ideally, at least it is a shared meal, gathered at a large table, which symbolizes family intimacy. Food in particular can be a reflection of ethnic or national identity.

One of the internal factors that influence behavior is knowledge. This knowledge in particular includes, intelligence, perception, emotion and external motivation. Education and knowledge are indirect factors that influence a person's behavior.
The knowledge that a person gains cannot be separated from education. Knowledge that is supported by adequate education will instill good habits. Mothers who have extensive knowledge can choose and provide direction to their children to choose the right, nutritious, balanced food and provide the basis for good and correct nutritional behavior regarding one's eating habits (Notoatmodjo, 2007 and Sediaoetama, 2000).

Factors that influence behavior include knowledge and attitudes. Knowledge of nutrition is also very influential on attitudes and behavior in choosing food, especially in choosing the right food, nutritious, balanced and providing the basis for good and correct nutritional behavior concerning one's eating habits (Sediaoetma, 2000).

The provision of nutritious food for toddlers is very important where parents must have knowledge of the provision of food intake that can make children grow well. The types of food that are often consumed by toddlers are soya milk, baby porridge, which are not difficult to obtain because they are very easy to obtain in the market.

To ensure a good future for toddlers' health, the fulfillment of nutrition for toddlers is not enough so it must be aligned with the fulfillment of healthy eating habits that must be formed as early as possible. It should be realized that healthy eating habits will be carried by toddlers into adulthood. Besides that, toddlers are individuals, so the shared habits that are formed must be appropriate between toddlers and their parents which are sought to be more flexible. So that until adulthood they will continue to carry eating habits that are applied from toddlers (Triton PB, 2006: 182).

Feeding baby is usually not based on a strict time setting, meaning that if the baby looks hungry which is marked by crying that does not stop, then the baby is immediately fed or breastfed. However, it is common practice to feed (breastfeed) babies four times a day, namely in the morning at 07.00 and 10.00 , in the afternoon at 13.00 and in the evening at 20.00 which is specifically for babies under three months. If the mother does not have enough breast milk, then instead SGM milk is purchased according to the age of the baby. Babies over three months old can be given additional food, such as this kind of porridge, if necessary, often also added with green beans. To add baby food and drinks, usually parents also give canned milk drinks that are inserted into the pacifier (M.A. Dewi Indrawati, 1991:85).

In providing food for toddlers, parents must pay attention to the nutritional content in food that is suitable for consumption according to their age. For example, at the age of 0-6 months, the only thing that must be given is breast milk or called exclusive 
breastfeeding, no complementary foods other than breast milk are allowed This is because the baby's stomach and intestines are not fully functional. Only after six months are given complementary foods, such as giving biscuits dissolved in hot water or made like porridge. To find out which foods are suitable for consumption by toddlers according to their age, parents are required to have good knowledge about it.

Nutritional anthropology is a branch or specialty of health anthropology, which focuses on the food culture system and the practical importance of the study of nutritional problems. His scope of concern includes human evolution, history, culture, and human adaptation to problems, food and nutrition in various environmental conditions. Generally, nutritional anthropologists study food issues as a complex of knowledge that determines whether or not it is permissible (musts and taboos), wisdom, production, preparation, consumption, and nutritional consequences (Kalangie 1985:45).

In addition, there are also some foods that should be avoided so that the toddler does not consume them, namely (Thompson, 2003: 7): (1) Foods that are harmful to the child's external digestive tract, including popcorn, fruits with small seeds, longan, and types of nuts, especially peanuts; (2) Foods and drinks that contain caffeine that can make toddlers nervous; (3) Foods containing spices, unless the child is used to it and asks for it himself; (4) Foods that are too salty that make your little one feel thirsty quickly.

Then, Thompson (2003:6) also classifies the main food groups of toddlers in the following composition: (a) Fats and sugars, which must avoid artificial sweeteners and provide high-fat dairy foods; (b) Meat and its alternatives, where each day is given 1 serving of meat, fish, or eggs, or 2 servings of plants such as beans; (c) Dairy foods, which should be given as little as $350 \mathrm{ml}$ of high fat milk or two servings of cheese or yogurt; (d) Fruits and vegetables, for which a minimum of 4 servings of fresh, canned or frozen fruits or vegetables are provided: (e) Grain and starch products, for which at least 1 serving of rice, bread, corn, cereals or herbs containing starches, and avoid very coarse grains.

Families as members of society actually have an obligation and responsibility to preserve food habits. Eating habits are a term to describe behavior related to eating and being eaten, beliefs about food (like it or not), how to choose food ingredients to be eaten (Suhardjo, 1989: 4).

People's behavior in choosing and determining the type, quantity of food may change due to sociocultural factors, particularly with regard to knowledge, values (tastes, satisfaction), norms, and beliefs. This change is related to increasing knowledge about nutrition and health, as well as the variety of processed food products that are practical (instant), cheap, and available, such as instant noodles. Therefore, the production of food supply must pay attention to changes in people's consumption patterns which are closely related to socio-cultural factors, especially in urban areas, where food consumption does not depend on rice.

Every community, by using it, is able to recognize various classifications of food, including: type, quantity, quality, method of preparation, and presentation. Examples of food clarification methods are: (1) breakfast, snacks/snacks, and complete meals, (2) daily meals in party/ceremonial meals, (3) food based on age and gender, (4) food according to circumstances health, illness, and curative care, (5) foods that are considered good for health and not good for the age group, (6) differences between staple foods and side dishes, (7) foods that are served fresh (raw) and those that are must be cooked, (8) food that can be served both fresh and cooked, and (9) the quality of hot and cold food (Nurcahyo Tri Arianto: 27-40),

Nowadays, parents rarely pay attention to proper food for toddlers to eat due to the busyness of their parents at work. The Batak Toba family also has the motto anakkonki do hamorao in au. So that makes them very inclined to look for money so that their children's needs are met without knowing the right foods to eat by toddlers. Here the parents leave the toddler or leave it to the neighbors, in order to earn a living to meet the needs of the toddler, which makes this toddler not aware of the choice of healthy food in his body, because it is very important to supervise parents who know about the food eaten by the child/toddler.

Because in the type of food, processing and serving, especially in Muliorejo Village, Sunggal District, where parents are less concerned in determining the type of food that is good for toddlers to consume. Parents' indifference in choosing food for toddlers is due to the lack of knowledge of the Batak Toba Family's parents about good food for toddlers to consume. Therefore, researchers are interested in researching "Knowledge about toddler food in Muliorejo Village, Sunggal District, Deli Serdang Regency".

\section{RESEARCH METHOD}

This study uses qualitative research methods (ethnography) to collect research data. The characteristics of this ethnographic field research method are its holistic-integrative nature, thick 
description, and qualitative analysis in order to obtain native's point of view (Marzali Amri, 2006: viii-ix). There are two kinds of data collected, namely primary data and secondary data. Primary data in the form of participatory observation and indepth interviews. The most important instrument in this participatory observation technique is the researcher himself, where a researcher must be able to build or place himself as an "insider" as well as an "outsider" from the community.

Qualitative research is a research method to explore and understand the meaning that some individuals or groups of people think come from social or human problems (Creswell, 2013). The final report of a qualitative study has a flexible structure or framework. The perspective used in this study is inductive style, focuses on individual meanings, and translates the complexity of a problem. In the world of education, qualitative research has the objective of describing the process of educational activities based on what is in the field as study material to find shortcomings and weaknesses so that efforts can be determined to improve them; analyzing a symptom, facts, and educational events in the field; compile a hypothesis related to the concepts and principles of education based on information and data that occur in the field.

Then, secondary data is in the form of library research, namely through scientific books or journals related to the research topic, documentation, as well as online/internet sources and other sources relevant to the research problem.

\section{RESULT AND DISCUSSION}

Food in Batak Toba language is known as "sipanganon", where according to the concept of the Batak Toba tribe, food is all organic products with biochemical quantities that physiologically function to maintain the life of the human body and have cultural meanings that are recognized and justified separately by members of each community groups. Eating (manganese) according to the tradition of Batak Toba tribe is eating rice along with the side dishes at a certain time.

The problem of food is not only related to the needs of the human body such as nutrition, calories and vitamins, but also concerns how to eat well, what to eat and what not to eat, and so on. So that the food given to toddlers is very important to know how the content of the food given or whether or not the type of food is good for toddler growth.

According to Anderson (1986: 313) states that anthropologists view eating habits as a complex of cooking activities, problems of difficulty and difficulty, folk wisdom, beliefs, taboos, and superstitions related to production, preparation, and food consumption.

In Batak Toba community, there is a pattern of obtaining, using, and evaluating food which will be a cultural feature of Batak Toba community. Generally, people give certain definitions of the meaning of food such as: there are types of food to sell and others to eat at home. Thus, eating culture is the behavior and eating habits, as well as the culture in choosing and determining the food consumed by the community based on certain views originating from hereditary customs that are still role models for the community.

Based on the results of interviews conducted by researchers, there are several types of food that are suitable for the age of toddlers, including:

a. Exclusive Breastfeeding

Breast milk is the most ideal food for babies, because it contains enough energy and sufficient essential nutrients (Pujjati, 2000). From the results of interviews with M. Halawa's mother and her husband P. Sianturi, she gave breast milk by habit when the baby cried and the baby would stop crying.

When the baby is three months old, some mothers give their children bottled milk, which is powdered milk which is usually sold in stalls. Exclusive breastfeeding means that the baby is only given breast milk without giving other food and drinks to the baby from birth until the baby is six months old, except for medicine and vitamins that are given to the baby (Sulistijani, 2001). Breastfeeding should generally be recommended for at least the first year of a child's life. The period of breastfeeding, according to Law number 36/2009 concerning breastfeeding, article 128 paragraph 1 , which states that "every baby has the right to get exclusive breast milk since birth for six months, except for medical indications" (Health Law, 2010).

b. Complementary Feeding

After the baby is 6-9 months old, babies are introduced to soft-formed complementary foods such as milk porridge, biscuits with water or milk added, bananas and mashed papaya. Babies are also still getting breast milk. In feeding the child, the mother will slowly introduce the food according to her growth, the child who has not been able to eat food that cannot be chewed like a parent during the day gives the child banana food, by means of the mother mashing the banana into her mother's mouth, and after that give it to the mouth of the child.

c. Steam Rice Food

At the age of the baby 9-12 months, breast milk is still given, then the mother introduces soft food, namely in the form of filtered rice/mixed porridge with a frequency of twice a day, in order to get high 
nutritional value in food, such as; baby team rice added little by little with a source of fatty substances, namely coconut milk or coconut oil / margarine. Even these foods can add calories to baby food, besides providing a good taste, it also enhances the absorption of vitamin A and other fatsoluble nutrients.

In Batak Toba family that the researchers studied, the child who could not eat hard rice, the mother mashed the rice into her mouth, then after it was mashed or mashed in the mouth, it was given to her child so that it was easier for the baby to swallow. This is still often found in the behavior of mothers in Batak Toba family.

After giving breast milk and team rice for the baby, the mother also provides snacks once a day that have high nutritional value, such as green bean porridge, fruits, cakes, and others. It was also found in the field, there were some mothers who cooked their own snacks such as mung bean porridge during the day, then fed them to their babies in the afternoon.

\section{d. Unmashed Steam Rice Food}

When the baby is $1-2$ years old, the mother has started weaning by reducing breastfeeding for the child. Giving complementary feeding or family food at least 3 times a day with a portion of half the adult food given to children at each meal. Besides that, the mother also continues to give snacks 2 times a day, so that the child does not starve and after continuing to eat other foods the child becomes a habit with it which will make the child no longer ask for breast milk from his mother.

\section{e. Ordinary Rice Food}

At the age of 2-3 years, children have begun to know and enjoy a variety of tastes, colors, and shapes of food. Where the mother has given the child to eat snacks that the child bought from a stall close to his house. The results of the study found that toddlers were eating at times outside of their proper eating hours, namely at 10:00 and 15:00, mothers of toddlers said that sometimes toddlers eat twice a day plus snacks and all are obeyed for the sake of a healthy child. In addition, researchers also saw mothers who gave their children food, often demonstrating by making their mouths as well as mothers chewing food just like toddlers. This habit is carried out until the child really understands the food that is given to him.

f. Green Bean Porridge Supplementary Food

In Muliorejo village community, there are many parents who make their children after the age of 3-5 years send their children to be fostered by including a playgroup, where parents have to make healthy breakfast for children.
Although this age group has been trusted to eat alone, without being fed at meal times, the role of parents is still needed in providing good supervision for children so that children stay healthy and awake. The mother must also pay attention to the provision of interlude or snack food for children who should not be close to the main meal time (at least 1 hour before eating). The types of food that parents give to the toddler are salmon, sweet potatoes, avocado, yogurt, citrus fruits, bananas, nuts, eggs, meatballs.

Furthermore, in the selection of food for toddlers, for infants aged 0-6 months only exclusive breastfeeding. There are one or two families who still provide additional, namely giving biscuits mixed into hot water after which it is shaken and then given to the baby.

Children under one year of age are given complementary foods (MPASI), such as soft foods in the form of porridge, such as milk porridge or fruit juice. When children have reached the age of 1 year, they are introduced to semi-solid foods such as nasi tim as a transition to solid foods. Supplementary foods to complement breast milk are in the form of semi-solid foods including carbohydrates, vegetables, fish and others.

Supplementary food is other than breast milk and formula milk (Widodo, 2010:49). The types of additional food recommended for toddlers are: (a) Rice flour/brown rice porridge, cooked using liquid water/meat/vegetable broth, formula milk, breast milk or liquid; (b) Flour porridge, either cornstarch cooked with broth or formula/breast milk; (c) Fruit purees or mashed fruit, such as bananas, papayas, melons, apples, avocados; (d) Puree vegetables, vegetables that are boiled and then mashed using a blender such as peas, kidney beans, carrots, tomatoes, potatoes, pumpkins; (e) Puree beans, kidney beans/ green beans/ peas boiled in broth until tender then mashed with a blender; (f) Lean meat; (g) Chicken, choose young free-range meat without bones, skin and fat; (h) Fish, choose boneless fish meat such as salmon fillet, snapper fillet and gindera.

Meanwhile, additional foods that are not recommended for toddlers are: (a) All types of foods containing gluten protein, such as wheat flour, barley, wheat germ, cookies from wheat flour and oatmeal that cause flatulence, nausea and diarrhea in infants; (b) Avoid giving sugar, salt, cooking spices/flavours to baby food; (c) Foods that are too fatty; (d) Fruits are too acidic, such as oranges, soursop; (e) Food is too spicy or spicy, avoid chili, pepper and tamarind; (f) Cow's milk and its products; (g) Fruits containing gas, durian, cempedak, trigger bloating and constipation; (h) Gassy vegetables, cabbage, cauliflower, radishes; (i) 
Peanuts; (j) Often eggs trigger allergies, give face to face with small portions and see the reaction. If it does not cause an egg allergy, it can be given (Nuraeni, 2009).

Furthermore, as for how to process food in children, namely:

1) For carbohydrate foods, the way to cook white rice is to cook or steam it, the important thing is that the rice is cooked until it is cooked with enough water. Meanwhile, how to cook brown rice, should be mixed with white rice to make it fluffier. How to cook corn is boiled with a little water for 10 minutes, then smeared with butter, salt, sugar. How to cook sweet potatoes is steamed and made pure (mashed).

2) For protein foods, the way to cook eggs is to boil until cooked (7-8 minutes) or quickly cook using a little oil and can be mixed with finely chopped vegetables. How to cook chicken is steamed for the soto mixture, stir-fried as a mixture of cap cay, soup, fried briefly after being seasoned or fried for a moment to become chicken pop. How to cook meat, preferably steamed or sauteed, therefore cut it into thin slices or chopped Do not fry because it will add to the already high fat content.

3) For vitamin and mineral foods, how to cook vegetables with vitamins $A, D, E, K$ (found in spinach, carrots, cassava leaves, kale, long beans, katuk, mustard greens, corn), if cooked with cooking oil, such as sauteing, do not be too long because the vitamins will run out. How to cook vegetables, vitamins C, B1, B2, B5, B12 (found in cassava leaves, katuk, melinjo, mustard greens, potatoes, celery, chives, long beans, cabbage, tomatoes) dissolve in water, therefore, if boiled or souped, do not too long because the vitamins will run out. Almost all vegetables, especially spinach, should be eaten immediately after cooking. Do not delay more than 2 hours. In addition to the damaged vitamins, it is feared that there will be a chemical reaction that makes the vegetables unfit to eat. As for how to process the fruit, the fruit should be eaten directly. If juiced, the fiber will be lost, if it is set, the vitamins are reduced when heated. Some fruits will have more vitamins if eaten with the skin, such as apples, pears and grapes.

In research in the field, babies start getting solid food after the exclusive breastfeeding period ends, which is 6 months.

a. Solid Foods for 6-9 Months Old

In the family, the researcher saw some parents making rice food for the team by buying carrots, spinach, and chicken, then cooking them in a small cooker by adding enough rice for the children and after the rice was a little soft, the mother mixed carrots, spinach, and chicken into it and let it simmer until the mixed rice, vegetables and chicken are already mushy. The mother also puts the child's food on a plate and then grinds it with a sieve.

Setting the schedule for breastfeeding and food is that if the baby is getting solid food, mothers reduce breastfeeding. First, give baby food as a substitute for drinking milk during the day. The mother does not breastfeed the baby when he has received solid food, which is to provide the baby with mineral water some time after he finishes his solid food.

b. 9-12 Months Baby Solid Food

At the age of 9-12 months puree the spinach that has been boiled first, then filtered. Mix red meat when making rice porridge with rice porridge. You can also add mashed chicken or carrots. Once cooked, strain until shaped like porridge. As a distraction, you can give mashed tomatoes or melons for a snack in the afternoon.

c. Solid Food For 1-2 Years old

At this age, babies have begun to be able to digest foods that are a little rough, that is, they can provide fruits and vegetables that do not need to be filtered, just mashed. Red beans, minced meat can be mixed with fine team rice. Sea fish can also be boiled for a team of rice mixture, or can be given pasta. During this time, the mother always provides a little cooking spices for the toddler.

d. Solid Foods for 2-3 Years Old

At this age, tuna that is in the steam or stewed has been given to children, mixed broccoli and beans, then gave children oranges and bananas as a complement. Parents have started to give the team's rice but it is no longer mashed with a blender. Vegetables, chicken, carrots and others are mixed into the cooked food and then given to the child after it has cooled down. Some mothers also serve special vegetables for children, namely clear vegetables.

e. Solid Foods for 3-5 Years Old

The data that researchers found in the field, that a mother who has a child aged 3-5 years has been given the same rice foods every day eaten by the family, only the difference is that in adult food, children's food is not made spicy which can make children sick to their stomach Parents have also provided side foods so that children do not eat outside, such as green bean porridge which the mother cooks herself. In addition, the researchers also found several mothers in Batak 
Toba family who had 2-year-old children who were entrusted to their families, who gave readyto-eat instant food to their children because they worked in factories.

Furthermore, as for the typical food of toddlers in the Batak Toba family that the researchers got in the field, as told by the informant Mr. R. Sihombing, that when the child was a baby or aged six months, he was given exclusive breastfeeding for six months, after over six months the child was given porridge by his mother who gave him porridge. cooked in a pan as a place for rice, then mother makes the halfcooked rice into a plastic cup and then mixes salt and tomatoes. The knowledge of parents used to make these foods because tomatoes give a sweet taste when mixed into children's food.

The process of giving toddler food to Batak Toba community is not immediately accepted by the child, where the child also has a sense of refusal when it is given, in this case Batak Toba community continues to introduce food to children which in the end the child likes the food given by his mother. When the baby is over one year old, the food starts to increase, especally the protein, namely porridge mixed with eggs or chicken liver without stopping breastfeeding.

At the age of two years the baby is no longer breastfeeding, so parents introduce canned milk for toddlers which is usually given three times a day, ie once in the morning; once in the afternoon and once in the evening. This canned milk can be given until the child is about five years old.

As for the knowledge of the Batak Toba family in feeding toddlers such as in the village of Muliorejo, it is very good, but it is important for mothers to pay attention to children's behavior when eating. If the child is able to eat by himself, the mother should look at hand hygiene in the child. In the observations that researchers saw in the field, there were irregularities in providing food, namely parents taking children's food and letting children eat everywhere. From what the researchers examined, when the child was able to eat on his own, the child was left to eat in an inadequate environment, such as an onion that was about to be peeled. With the habit of the mother's behavior in giving food to the child, it will become a habit for the child when eating, there is no longer for the child to live a In addition, from the results of interviews with the parents of $\mathrm{Mr}$. Nababan whose child is 1 year and 3 months old, that the child has been fed by his mother at 08.00 am. But after that, the mother gave her son the snacks he bought at the shop. Children are not given regular food, so it is a mother's habit to give children snacks after eating which affects the child's dietary habbit.
Then, there is also the provision of food in the mother's family. C. Sigalingging who has a child, Antonius Sigalingging, aged 1 year and 3 months. In this family, children take precedence over their parents. The way to feed the child is by showing the mother opening her mouth when feeding the child, the child will also see how the mother opens and chews the food that enters the mouth.

Furthermore, from the results of interviews in the village of Muliorejo, various types of food are given starting from babies aged 0-6 months, only exclusive milk but there are still some who are given SGM milk because of the lack of breast milk for nutritional adequacy for children, after 6-9 months. Breast milk is still being continued but the mother has made additional baby food such as team rice which is made from rice, vegetables, and salt which is cooked until soft and after that, the mother mashes the rice using a sieve. After 9-1 years old, they have introduced fruit, namely bananas, where these bananas are given for fruit to meet children's food and are also soft and sweet. 1-2 years Mother has made porridge to the child and gave fruit that the child can hold. 3-5 years Mother gives hard rice but with a note not to make chili into the food that will be given to children.

Mother's knowledge in the village of Muliorejo about good diet and nutrition for children and also a healthy environment is very important for child growth and development.

\section{CONCLUSION}

The main point in the knowledge of Batak Toba families in feeding toddlers is that the food given to children is good, where parents already know to give the best for their children's food. In breastfeeding, mothers always provide additional food such as fried rice (purik). provide additional food such as powdered milk that is sold in the market or nearby shops. When the child is 3-5 years old or who already understands good food, in choosing this food, parents must be more careful when giving snacks to children, because children must have a balanced diet life, where in the field it is very likely that children after eating the child is given more snacks for the child, even though the child is just ready to eat and then provides additional food again in the near future. Where when the child gets used to the additional eating patterns given such as giving the child another meal after they are ready to eat, it will be disturbed in the child's eating pattern, where when the child is full of snacks given to the child, surely the child will refuse what is the main food child. Mother's knowledge in feeding this must also 
look at the environmental conditions when the child eats, because the environment is dirty and the child eats in such a place, the child will also do that habit when the child is always left to eat like that So it is very important for mothers in Muliorejo village that it is important to clean a healthy environment so that children have a healthy lifestyle, where the environment can affect children so that children get used to the atmosphere they get.

\section{REFERENCES}

Anderson. 1986. Health Anthropology. Universitas Indonesia. Jakarta.

Bangun, R. S. B., \& Bangun, S. (2021). Kuning in karo Community: Medical Anthroplogy Study in Bunuraya Village, Tiga Panah District, Karo Regency. Indonesian Journal of Medical Anthropology, 2(1), 53-56.

Indrawati, Dewi. 1991. Regional Children Parenting of Lampung. Department of Education and Culture Directorat General of Culture. Lampung.

Kalangi, Nico S. 1985. "Food as Cultural System; Some Subjects of Attention of Nutrition Anthropology", in Koentjaraningrat (ed), "Social Sciences in the Development". Gramedia. Jakarta.

Mulyono Notosiswoyo, Agus Suprapto, J.M. Umboh, Abd. Razak Thaha. 2001. JournalResearch Review of Traditional Fractures.
Sembiring, S. (2015). Knowledge and Usage of Traditional Treatment Method in Suka Nalu Village Coommunity, Barus Jahe District. Perspective of Sociology, 3(1), 156771.

Sembiring, L. C. (2013). Bawang Fracture Shaman The Traditional Treatment of Karo Community at Tiga Panah Village, Karo Regency (Doctoral Dissertation, Unimed).

Surbakti, E. B. (2014). Cultural Value in leksikon erpangir ku lau tradition of Karo Tribe (Study of Antropolinguistic). Link of Language and Literature Bahasa dan Sastra, 8(1), 95-107.

Surbakti, H., Sinar, T. S., Lubis, S., \& Muchtar, M. (2015). Translation Techniques of Traditional Karonese Medical Text on Fractured Bone Setting. US-China Foreign Language, 13(12), 879-894.

Notoatmodjo. 2005. Health Promotion and Behavioral Sciences. Rineka Cipta. Jakarta

Sediaoetama, Achmad Djaelani. 1989. Nutrition Science. Volume II. Dian Rakyat. Jakarta. 